\title{
Weight management in dogs and cats
}

\author{
Alexander J German \\ From Animal Obesity - causes, consequences and comparative aspects \\ Uppsala, Sweden. 14-16 June 2015
}

Obesity is defined as an accumulation of excessive amounts of adipose tissue in the body, and predisposes to a variety of diseases including diabetes mellitus, and osteoarthritis. In most animals, obesity is the result of a simple imbalance between energy intake and energy expenditure. Therefore, at its simplest, successful management of obesity usually involves reversing this imbalance by reducing energy intake and/or increasing energy expenditure. This lecture will discuss current thoughts on both conventional and novel treatments for of obesity in dogs and cats, and stimulate discussion on factors required for long-term success.

Published: 25 September 2015 